\title{
Precession Electron Diffraction based TEM Studies of Microstructure Evolution in Severely Plastically Deformed Austenitic Stainless Steel
}

\author{
Y. Idell and J.M.K. Wiezorek
}

Department of Mechanical Engineering and Materials Science, University of Pittsburgh, Pittsburgh, PA, USA

Austenitic stainless steels offer good property combinations for structural component applications in demanding and aggressive environments, including nuclear power plants, where irradiation assisted degradation failures have been reported [1]. Enhanced irradiation tolerance has been reported for materials containing a high density of internal interfaces that act as point defect annihilation or sink sites [2]. Utilizing methods of severe plastic deformation (SPD) grain refinement in austenitic stainless steels to the sub-micron and nanometer scale have been reported [3]. Establishing quantitatively relationships between processing parameters, microstructrual metrics (e.g. grain size, internal strain, grain boundary character distributions and texture) and properties of strongly grain refined bulk polycrystalline aggregate materials after SPD requires experimental tools with nanometer spatial resolution that can deliver statistically significant and representative data sets. SPD typically results in non-equilibrium microstructures, typically containing significant cold-deformation strain, excess defect density in grain interiors and in the grain boundaries, while also exhibiting down to nanometer scale refined grain size [3]. Due to the combined effects of these characteristics ascertaining respective microstructural metrics, e.g. grain size, by conventional methods based on X-ray diffraction (XRD), scanning electron microscopy (SEM) electron backscatter diffraction based (EBSD) orientation imaging microscopy (OIM) or diffraction contrast transmission electron microscopy (TEM) imaging often proves difficult.

Here we report and discuss the evolution of the nano-scaled grain structure of 316L stainless steel after SPD by linear plane-strain machining, a novel severe plastic deformation process [4] in response to isochronal annealing treatments at temperature up to $650^{\circ} \mathrm{C}$. Prior studies reported improved mechanical strength in the plane-strain machining processed $316 \mathrm{~L}$ with nano-scale average grain size and limited formation of strain-induced $\alpha^{\prime}$-martensite [5]. We used an automated systems for acquisition and indexing of precession electron diffraction (PED) patterns (ASTAR, Nanomegas [6]) in the TEM to characterize changes in the grain scale and morphology, phase fractions of a'-martensite, and texture as well as grain boundary structure. The indexing of the PED patterns proved robust despite of the presence of high-density populations of SPD induced crystal defects. Use of focused electron probes with diameters of $\sim 20 \mathrm{~nm}$ in a LaB6 gun and $\sim 2 \mathrm{~nm}$ in a field-emission gun equipped TEM permitted nanoscale spatial resolution OIM for studies of the thermal stability of the nanoscale grain size refined SPD prepared 316L. Complementing the PED TEM OIM experiments, conventional TEM, XRD, magnetometry and mechanical property measurements have been performed. This facilitates determination of processing-structure-property correlations for the annealed SPD prepared 316L.

Figure 1 shows examples of PED TEM OIM data sets of the microstructure of the SPD prepared $316 \mathrm{~L}$ material after $1 \mathrm{~h}$ annealing at $400^{\circ} \mathrm{C}$ and $600^{\circ} \mathrm{C}$. During the plane-strain machining based SPD shear strain equivalents of $\gamma \approx 2.1$ have been imparted at shear strain rates of $\mathrm{d} \gamma / \mathrm{dt} \approx 1.7 \times 10^{3} \mathrm{~s}^{-1}$ for the annealed states shown in Fig. 1(a) and (b), and of $d y / d t \approx 8.3 \times 10^{2} \mathrm{~s}^{-1}$ for those shown in Fig. 1 (c) and 
(d), respectively. The strain rate difference had negligible effects on the grain size, $\sim 45 \mathrm{~nm}$ (average of minor and major dimensions), $\alpha$-martensite fractions, $\sim 3 \mathrm{vol} \%$, and Vickers hardness, $\sim 1.65 \mathrm{GPa}$, of the as-deformed states. Isochronal $1 \mathrm{~h}$ annealing up to $500^{\circ} \mathrm{C}$ resulted only in minor coarsening of the average grain size without significant morphological change in the somewhat elongated, presumably ellipsoidal grain shapes obtained after SPD (Fig. 1). The $\alpha^{\prime}$-martensite fractions remained constant for the $350^{\circ} \mathrm{C}$ annealing and reduced to $\sim 1.5 \mathrm{vol} \%$ for the higher annealing temperatures. Hardness values were maintained at about $1420 \mathrm{GPa}$ and $1250 \mathrm{GPa}$ for the $600^{\circ} \mathrm{C}$ and $650^{\circ} \mathrm{C}$ annealed states, respectively.

\section{References}

[1] Kenik, E.A., Busby, J.T. Mat. Sci. Eng. R 73 (2012) p.67

[2] Nastasi et al. irradiation tolerance $\mathrm{CuNb}$ nanolayers

[3] Wang, H, et al., Mat. Sci. Eng. A 556 (2012) p.906

[4] Swaminathan, S, et al., Metall. Mat. Trans. A 38 (2007) p.1899

[5] Idell, Y, et al., Scripta Materialia 68 (2013) p.667

[6] Portillo J, et al., Materials Science Forum 644 (2010) p1

[7] The authors gratefully acknowledge funding support from the Nuclear Regulatory Commission, Graduate Fellowship Grant (Grant No. NRC-38-09-935).
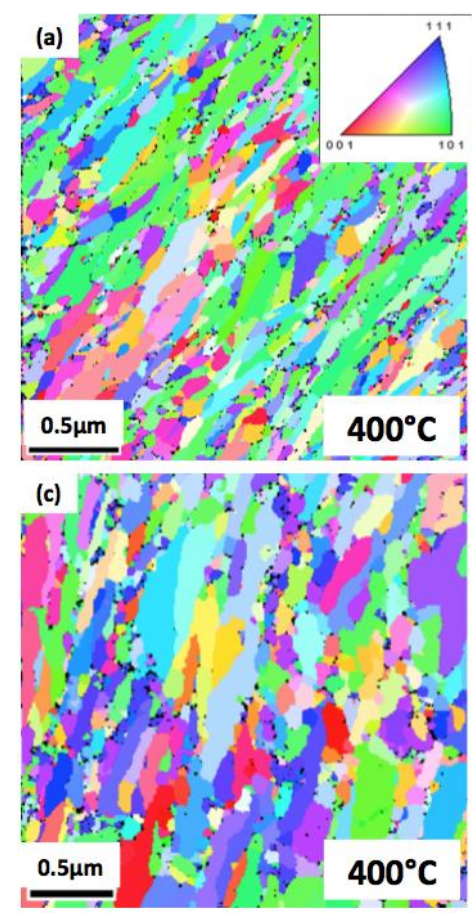

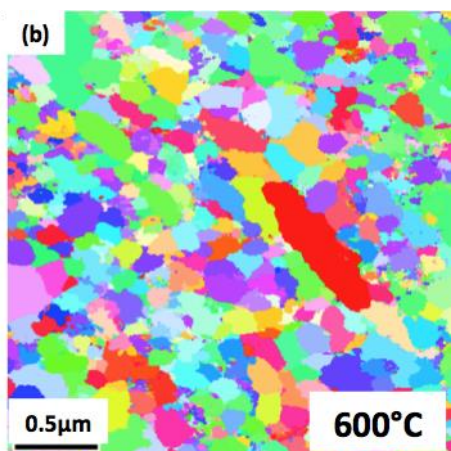

(d)

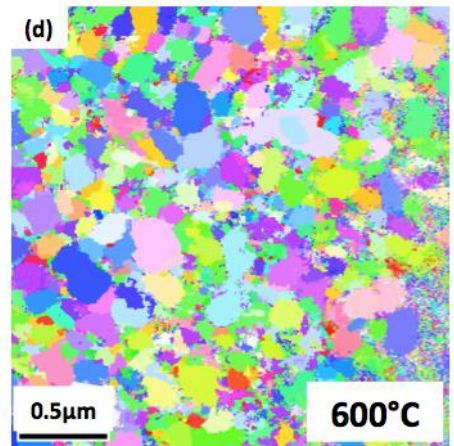

FIG. 1: Example PED TEM OIM data sets illustrating the nano-scale spatial resolution, for annealed states after plane-strain machining based SPD of 316L for (a) and (b) with a shear strain equivalent of $\gamma \approx 2.1$ at a rate of $\mathrm{d} \gamma \approx / \mathrm{dt} \approx 1.7 \times 10^{3} \mathrm{~s}^{-1}$, and for (c) and (d) with a shear strain equivalent of $\gamma \approx 2.1$ at a rate of $\mathrm{d} \gamma / \mathrm{dt} \approx 8.3 \times 10^{2} \mathrm{~s}^{-1}$. Inset in (a) standard triangle based orientation legend for the color-based inverse pole figure maps in (a) to (d). Scale markers of $0.5 \mu \mathrm{m}$ for all. 